\title{
A Semantic Analysis of Corona Virus Pandemic Terms
}

\author{
Lydia Udeme Edet ${ }^{\circledR}$ \\ Rosemaary Ugonma Babatunde ${ }^{2}$ (D) \\ Charles Ogbulogos \\ Innocent Chiluwa ${ }^{4}$
}

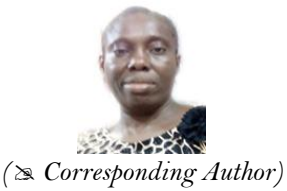

${ }^{1,2, s, 4}$ Department of Languages and General Studies, Covenant University, Nigeria. Email: lydia.edet@stu.cu.edu.ng

Email: rosemarybabatunde16@gmail.com

Email:charles.ogbulogo@,covenantuniversity.edu.ng

${ }^{*}$ EMail: innocent.chiluwa@covenantuniversity.edu.ng

\section{Abstract}

Various epidemics in recent years have introduced myriad of challenges to the entire world. COVID-19 disease is the latest crisis with its attendant health and language issues. With its emergence, COVID-19 introduced into the global linguistic repertoire an avalanche of unknown vocabulary to the ordinary language user. In today's world, language is not only available for communication; it is a tool that contributes to maintaining global peace and order. In bridging diverse communities of humanities in the world, shared meaning becomes a platform for mutual understanding, promoting intellectual development and collaborative research efforts. The current study aims to explore and explicate the novel language of COVID-19, thereby making meaning accessible for clarity of communication. The qualitative method of analysis which relied on secondary data from different online COVID-19 glossaries was utilised. Data collection was a total of 149 terms, out of which 34 were purposively selected for analysis. This was to examine their semantic meaning and also ascertain their word relations. The study investigates the process of developing meaning mechanisms in the use COVID-19 terms among language users. The study found that the COVID-19 has a distinct vocabulary that can be analysed linguistically. The literature review in this study highlighted past researches on COVID-19 as descriptive, others on the frequency count of words and the etymology of terms.

Keywords: COVID-19, Epidemics, Glossaries, Language, Register theory, Semantics, Vocabulary.

Citation | Lydia Udeme Edet; Rosemaary Ugonma Babatunde; Charles Ogbulogo; Innocent Chiluwa (2021). A Semantic Analysis of Corona Virus Pandemic Terms. Asian Journal of Social Sciences and Management Studies, 8(3): 77-82.

History:

Received: 27 May 2021

Revised: 23 July 2021

Accepted: 16 August 2021

Published: 13 September 202

Licensed: This work is licensed under a Creative Commons Attribution 3.0 License (oc) E)

Publisher: Asian Online Journal Publishing Group
Acknowledgement: All authors contributed to the conception and design of the study.

Funding: The authors wish to express gratitude to the management of Covenant University and Covenant University Centre for Research, Innovation and Discoveries (CUCRID) for sponsoring the publication of this article. Competing Interests: The authors declare that they have no conflict of

Transparency: The authors confirm that the manuscript is an honest, accurate, and transparent account of the study was reported; that no vital features of the study have been omitted; and that any discrepancies from the study as planned have been explained.

Ethical: This study follows all ethical practices during writing.

\section{Contents}

1. Introduction

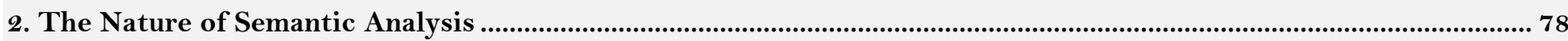



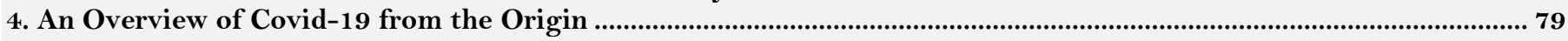

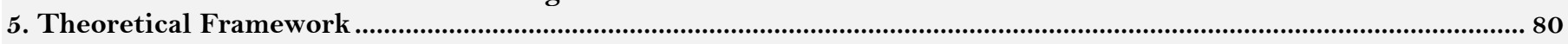

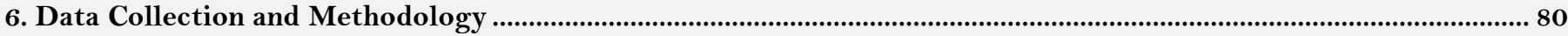

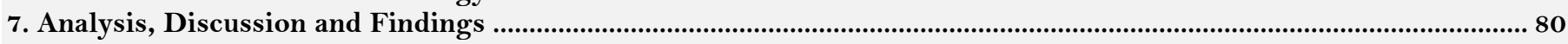

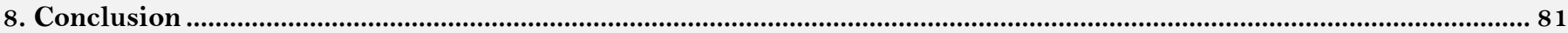

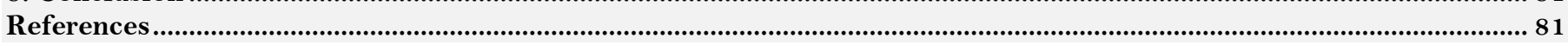




\section{Contribution of this paper to the literature}

This is one of very few studies that investigated the novel COVID-19 disease from a semantic perspective. Semantics provides shared meaning which impacts on communication. In addition, vocabulary learning which this study provides contributes to the use of English as a global language and also offers linguistic solutions to contain the spread of coronavirus. This is only possible when one has a good understanding of the terms. The study also presents a rare interdisciplinary combination of different fields such as medicine, virology, computer, and linguistics to strengthen meaning. This has implications for global peace, public safety and sustainable development.

\section{Introduction}

A major epidemic in the $21^{\text {st }}$ Century associated with current global crisis- is the COVID-19 disease. The emergence of this pandemic brought with it an avalanche of linguistic resources that comprises words used as labels for naming diseases and related terms. This connection has brought to the fore, a large and confusing vocabulary which is quite novel and confusing to the ordinary language user. Semantics, the science of meaning appears a ready tool that can proffer solution to this linguistic challenge. This is in order to have a common platform of meaning and understanding in everyday communication. Apparently not much has been done to explicate the language of COVID-19 from a semantic perspective. Even the study by publishers of Oxford English Dictionary appears merely descriptive with the emphasis on frequency counting. Another research into COVID-19 terms by Asif, Zhiyong, Iram, and Nisar (2020) investigated the etymology of the terms which is morphologically based. Perhaps, a more enriching explication will emerge with a deliberate and systematic semantic analysis from this current study. Moreover, health is very essential in achieving societal goals as highlighted in the United Nations Sustainable Development Goal (SDG) (Oyeyemi, Gberevbie, \& Ibietan, 2021) hence the need to explicate the COVID-19 terms, their meaning and any existing word relations among them. These demands for clarity and ease of communication form the justification for this study.

Semantics, the study of meaning is crucial to language and communications. It is widely acknowledged that language, a creative human behaviour distinguishes man from other higher animals (Abioye, 2018). Language also contributes to the socio-economic and political development of any nation (Chiluwa \& Odebunmi, 2016). As reported by some scholars, meaning was a core subject of investigation to the early philosophers. This interest by philosophers highlight meaning as a central concern of philosophy in the early 2oth century. That development was attributed to an interaction of several trends in different disciplines such as Mathematics.

In this connection, the German mathematician Gottlob Frege and the British philosopher Bertrand Russellextended their inquiry of logic, the formal study of reasoning, into the domain of the natural languages, as the original media of human reasoning. This collective efforts in the mathematical domain, combined with mathematical logic impacted on developments in the study of semantics (The Editors of Encyclopaedia Britannica, semantics | Definition \& Theories | Britannica). In contrast, linguists studied meaning solely in relation to language. Thus, semantic analysis remains a critical assignment for meaning to be maximized.

In literature, the nature of semantic analysis is explicated along two main lines of considerations: the technological domain and the linguistic domain (Edet, 2020). This study has inclinations for the linguistic aspect of semantic analysis. In the technological aspect, semantic analysis which is computer based entails the process whereby meaning representations are composed and assigned to linguistic inputs. This is accomplished through a wide range of knowledge-sources and inference techniques such as meanings of words, the meanings associated with grammatical structures and knowledge about the structure of the discourse. Other techniques include knowledge about the context in word where the discourse occur and common-sense knowledge about the topic concerned. However, this study is concerned with the meaning of COVID-19 terms and its relations. This becomes vital as the novel COVID-19 global pandemic with its diverse and confusing terminologies has printed indelible marks on the vocabulary and lexicon footprints of the world. Thus, the semantics of English language proffers solution to explicate these terms through a descriptive analysis.

\section{The Nature of Semantic Analysis}

Semantics, as a branch of linguistics, aims to study the notion of meaning in language. Language demonstrates a meaningful message because of the semantic interaction with the different linguistic levels, phonology (phones), lexicon and syntax. Semantic analysis deals with the meaning of words and sentences, which refers to the elements in the world (Rajani \& Hanumanthappa, 2016). Although semantic analysis can be carried out on different platforms of truth based semantics, referential, ideational, conceptual, structural, transformational and lexical. However, this study is based on the premise of lexical semantics which concerns itself with the meanings of words and fixed word combination, such as COVID-19 terms. A look into some existing views on the concept of semantics seems quite revealing.

In linguistics, semantic analysis is the study of the structure and meaning of speech that relates syntactic structures, from the phrases, clauses, sentences, paragraphs levels to the entire writing and their languageindependent meanings. This is achieved by examining the text from the writer's point of view where the author's choice of language structure is unravelled and justified (Goddard, 2013). In this connection, semantic analysis identifies words already present in a text to arrive at meaning in communication. This aligns with Varone, Mayer, and Melegari (2017) views that we understand the meaning of a text through established knowledge about language itself and the concepts available in that text.

Goddard and Schalley (2010) opines that semantic analysis entails analyzing the meanings of words, fixed expressions, whole sentences, and utterances in context. In real terms, it means when original expressions are translated into some kind of semantic metalanguage. Semantic analysis is the tool for description in order to make exact meaning accessible and also relate syntactic structures. As such meaning in this context remains determinate and a ready tool in the prevention of COVID-19 spread. 
Varone et al. (2017) opine that semantic analysis describes the process of understanding natural language, the way humans communicate which is based on meaning and context. As such, semantic analysis enables a complete understanding of meaning in text.

The foregoing discussions emphasize the import of meaning in communication as well as in natural languages. From the opinions of scholars, it is apparent that the analysis of words enables an understanding in the context of its usage. Their views also justify the essence of this study which is a semantic analysis of COVID-19 terms.

As observed, the practice of semantic analysis can either be technological or linguistic. In the technological domain, it is ICT driven and computer based. In this regard, semantic analysis entails the process whereby meaning representations are composed and assigned to linguistic inputs (Huang, Wang, Chang, Hwu, \& Xiong, 2020; Meštrović, Martinčić-Ipšić, \& Čubrilo, 2007). To create rich and accurate meaning representations, a wide range of knowledge-sources and inference techniques are involved. These include meanings of words, the meanings associated with grammatical structures, knowledge about the structure of the discourse. Others are knowledge about the context in word where the discourse occurs and common-sense knowledge about the topic concerned.

In linguistics, semantic analysis is the study of the structure and meaning of speech. It also involves relating syntactic structures at the levels of phrases, clauses, sentences and paragraphs to the level of the writing in a bid to discover their individual meanings. Therefore, semantic analysis gives meaning to a work of literary composition as the author's choice of language structure is highlighted and justified. In this connection, semantic analysis uses words already present in a text to arrive at meaning in communication. This aligns with Varone et al. (2017) views that we rely on what we already know about language itself and the concepts present in a text to understand what the text highlights. The foregoing discussions emphasize the import of meaning in natural languages. From the opinions of scholars above, it is the analysis of words that enables an understanding in the context of its usage.

\section{An overview of Global Pandemics in Human History}

The world has recorded an avalanche of public health challenges from the prehistoric times till date. History has it that many lives were lost through various outbreaks in prehistoric times through various epidemics. An account of some relics of the prehistoric epidemics include archaeological sites such as "Hamin Mangha" and Miaozigou. The former is one of the best-preserved prehistoric sites in northeastern China where an epidemic wiped out a prehistoric village in China about 5,000 years ago, and the bodies of the dead were stuffed inside a house. Miaozigou another prehistoric mass burial that confirms the brutality of an epidemic is located in northeastern China. In brief, some of the worst epidemics and pandemics, dating from prehistoric to modern times includes: Spanish flu: the deadliest pandemic in history, Plague of Athens: 430 B.C., Antonine Plague: A.D. 165180, Plague of Cyprian: A.D. 250-271, Plague of Justinian: A.D. 541-542, The Black Death: 1346-1353, American Plagues of the16th century. The emergence of modern plagues date back to 1916 with the emergence of American polio epidemic. Others are Asian Flu: 1957-1958, AIDS pandemic and epidemic: 1981-present day, H1N1 Swine Flu pandemic: 2009-2010, Zika Virus epidemic: 2015-present day. Historically, the Spanish flu pandemic of 1918-1920 ranks the deadliest influenza outbreak in modern history, killing between 50 and 100 million people (Jarus, 2020).

Other challenges directly related to health include hunger/malnutrition, non-communicable diseases, maternal and child mortality, road accidents among others. Communicable diseases that have the potential to become epidemics or pandemics include influenza, caused by influenza viruses such as the $\mathrm{H} 5 \mathrm{~N} 1$ virus outbreak in 2003, the H1N1 epidemic in 2009, and the ongoing H7N9 epidemic in China (Jarus, 2020). Ebola which originated from the West Africa region in 2013 is reported to have destabilized whole countries and paralyzed the healthcare systems in countries such as Guinea, Liberia and Lome. This epidemic led to deaths and loss of economic activities in the affected counties.

The popular epidemics which have come to stay are HIV/AIDS, Ebola and SARS. The Acquired immunodeficiency syndrome (AIDS) is a chronic, potentially life-threatening condition caused by the human immunodeficiency virus (HIV) which damages the human immune system, thereby making an individual prone to infections and diseases since the body has no ability to fight. At present, there is steady decrease in global number of people dying from AIDS-related causes, from 2.3 million in 2005 to 1.6 million in 2012. As a major health crisis in parts of Africa, HIV/AIDS accounts for about 70 percent of global deaths.

\section{An Overview of Covid-19 from the Origin}

The index case of corona virus was identified as cold in 1960. As observed by the Canadian study in 2001, 500 patients were identified with a flu-like system. Through the use of polymerase chain reaction, 17-18 cases of the patients were confirmed as infected with corona virus strain which was then treated as simple and nonfatal virus till 2002. In 2003, various reports were published with the proofs of spreading the corona to many countries such as United States of America, Hong Kong, Singapore, Thailand, Vietnam and Taiwan. In addition, coronaviruses are believed to exist in certain species of animals, such as cattle and camels (Kandola, 2020). On 31 Dec. 2019, China, most populated country in East Asia, reported to WHO some pneumonia cases with strange etiology (Kumar, Malviya, \& Sharma, 2020). Since its discovery, more than 2,850,000 cases have been infected, with nearly 200,000 deaths (Guo et al., 2020). Moreover, coronaviruses are well-known to mutate and recombine (Alanagreh, Alzoughool, \& Atoum, 2020).

The COVID-19 is the third novel coronavirus to cause a large-scale epidemic in the twenty-first century after the Severe Acute Respiratory Syndrome Coronavirus (SARS-CoV) in 2003 (De Wit, van Doremalen, Falzarano, \& Munster, 2016) and the Middle East Respiratory Syndrome Coronavirus (MERS-CoV) in 2012 (Alanagreh et al., 2020). SARS-CoV is the virus strain that causes COVID-19. The recovery rate of people with COVID-19 is around $80 \%$ without specialist treatment. These people may experience mild flu-like symptoms. However, 1 in 6 people may experience severe symptoms, such as difficulty in breathing. With the recent outbreak in Wuhan, a city in the Hubei province of China in December 2019, corona virus became a global pandemic claiming millions of lives.

It was The International Committee on Taxonomy of Viruses (ICTV) that announced "severe acute respiratory syndrome coronavirus 2 (SARS-CoV-2)" as the name of the new virus on 11 February 2020. This name was chosen because the virus is genetically related to the coronavirus responsible for the SARS outbreak of 2003. While 
related, the two viruses are different. The first human cases of COVID-19, the disease caused by the novel coronavirus causing COVID-19, subsequently named SARS-CoV-2 were first reported by officials in Wuhan City, China, in December 2019.

\section{Theoretical Framework}

The term 'Register' has varied definitions by different schools of thoughts but with some commonalities (Nutakor, 2013). For instance, Deng, (2020); Nordquist, (2018); Szmrecsanyi \& Leuven, (2019) identifies register as the way a speaker uses language differently in different circumstances. Gregory and Carroll (2020) defines register as a theory of language variation according to situational contexts. According to Niazi (2016) a register is a variety of a language used for a particular purpose or in a particular social setting. Neumann (2016) opines that register in the systemic sense is functional variation of language use in a given context of situation. From the definitions, it is arguable that context is the common denominator that determines the occurrence of variation in language. In other words, the situation or event determines the degree of formality in the language use. This study adopts (Niazi, 2016) views that uphold the varieties of language (the core vocabulary) in specific contexts such as medical in which COVID-19 exists.

The register theory is among the core concepts in Systemic Functional Grammar (SFG) where the social and cultural role of language is a major concern. SFG is a functional theory of language that establishes language as a socio-semiotic system (Soares, 2017). It also describes the organisation of the 'meaning-making resources' used to achieve language and communication goals Halliday \& Matthiessen (2004 in Chong (2011)). It is believed that Halliday and other linguists further developed the concept of register in order to identify different variations in language according to the user. In addition, the SFG model highlights the structuring of language to achieve sociocultural meanings (Djachy, Kuparadze, \& Rukhiashvili, 2018; Ikupa \& Akpere, 2019) and the use of language by interactants to accomplish tasks in everyday social life Coffin (2001 in Ling (2013)); Ahamada, Jauharib, Luddinc, and Abdurahmand (2019); Korneeva, Kosacheva, and Parpura (2019). In other words, a mastery of registers in any specific or professional context implies clarity and ease of communication. This is very practicable in the use of COVID-19 terms which demands shared meaning in the fight against this global pandemic. It is in the use of the appropriate register cum language that the novel disease can be curbed.

This has to do with appropriate linguistic choices made from a set of systems containing structures (Chong, 2011). For instance, words such as 'Hydroxychloroquine, Favipiravir, Dexamethasone, Lopinavir in everyday communication denote the context of a pharmacist; and also indicate the semantic field of drugs and medications. On the other hand, lexical items such as aerosol, coronavirus, droplets, social distancing highlights the context of the current COVID-19, global pandemic. This upholds (Halliday, Teubert, Yallop, \& Cermakova, 2004) views cited in Mayes (2003) that meaning should not only be analyzed within the linguistic system, but the social system in which it occurs should be taken into consideration. The social system aligns with Bennet (2013) that words must have a shared or conventional meaning to serve as a means of communication between people.

In this regard, people make predictions about the meanings of utterances based on the vocabulary used in the context (Mayes, 2003).

Among the features of registers are specialized vocabulary and turns of phrases, colloquialisms and the use of jargon (Nordquist, 2018; Polyakova, Yuzakova, Suvorova, \& Zharova, 2019). Jargon creates and maintains connections among professionals 'who see themselves as 'insiders' to exclude 'outsiders' (Nugrahanto, 2017). These connections are maintained through the use of occupational registers, such as "asymptomatic, epidemic, coronavirus, incubation period, which are core lexical resources in the COVID-19 vocabulary.

\section{Data Collection and Methodology}

A study that intends to popularize and share meanings for global acceptability requires standardize linguistic data. As such this study relied on secondary data posted online from different COVID-19 glossaries. Data was collated through a download of the selected glossaries from their online sites into an MS-Word folder. After which each of the three glossaries were printed out in hard copies to enable computation of the word entries. Specifically, a total of 149 terms were derived from WebMD Medical Coronavirus: Glossary of Common Terms, COVID-19 crisis catalog: A glossary of terms and Unbound Medicine Coronavirus Glossary of Terms. In this connection, WebMD Medical Coronavirus Glossary presented 42 terms, COVID-19 crisis catalog glossary had 48 terms while Unbound Medicine Coronavirus Glossary highlighted 59 terms. All the three glossaries were compiled in 2020 and retrieved in 2021. The qualitative analysis describes each term and also highlights the word relations represented on tables. Out of the 149 words retrieved from the glossaries, only 34 COVID-19 terms were purposively selected since they have relations with other words. The data sources and numerical frequency are indicated on the Table 1.

\begin{tabular}{l|l|c|c}
\hline \multicolumn{3}{|c}{ Table-1. Sources of Data and numerical frequency. } \\
\hline 1 & Glossary & Number of Items & Remarks \\
\hline & $\begin{array}{l}\text { WebMD Medical Coronavirus: Glossary of } \\
\text { Common Terms }\end{array}$ & 42 & Author: Nazario (2020). \\
\hline 2 & COVID-19 crisis catalog: A glossary of terms & 48 & Author: Becker (2020). \\
\hline 3 & $\begin{array}{l}\text { Unbound Medicine } \\
\text { Coronavirus Glossary of Terms }\end{array}$ & 59 & \\
\hline
\end{tabular}

\section{Analysis, Discussion and Findings}

The purpose of this research was to explore the meaning of COVID 19 terms and also highlight the existing meaning relations. As such a total of 34 COVID-19 terms were purposively selected from the 149 terms extracted from the glossaries. In this regard, the researchers followed the traditional method of semantic analysis which highlights the meaning and relationship among words. The data were then carefully examined by the researchers based on their definition and relations. Only terms related to COVID-19 situation were purposively selected for the 
analysis. In this connection, Covid-19 related terms were analyzed in tabular form, listing the conceivable antonyms and synonyms with the meaning of each word.

\begin{tabular}{|c|c|c|c|c|}
\hline $\mathbf{S} / \mathbf{N}$ & Words & Synonym & Antonym & Meaning \\
\hline & Aerosol & Droplet & solid & $\begin{array}{l}\text { A tiny moist particle that is released } \\
\text { when you cough or sneeze. }\end{array}$ \\
\hline & Antibody test & serology test & - & $\begin{array}{l}\text { This type of test checks to see if one } \\
\text { has antibodies in the blood that shows } \\
\text { an early infection with the virus. }\end{array}$ \\
\hline & Asymptomatic & $\begin{array}{c}\text { Lack of } \\
\text { symptoms/Symptomless }\end{array}$ & symptomatic & Not showing symptoms of COVID-19 \\
\hline & Communicable & Contagious & Non-contagious & $\begin{array}{l}\text { Used to describe diseases that can be } \\
\text { spread or transmitted from one person } \\
\text { to another }\end{array}$ \\
\hline & Community spread & Wide Circulation & Unexpended & $\begin{array}{l}\text { The spread of an illness within a } \\
\text { particular location, for instance within } \\
\text { a neighbourhood or town. }\end{array}$ \\
\hline & & & $\begin{array}{l}\text { Unfilled/ } \\
\text { spacious }\end{array}$ & \\
\hline & Corona virus & $\mathrm{CoV}$ & - & $\begin{array}{l}\text { A type of virus that looks like a corona } \\
\text { (crown) when viewed under a } \\
\text { microscope. }\end{array}$ \\
\hline & COVID-19 & coronavirus disease & - & $\begin{array}{l}\text { The name of the infection caused by } \\
\text { the novel strain of coronavirus. }\end{array}$ \\
\hline & $\begin{array}{l}\text { Congregate } \\
\text { settings }\end{array}$ & Crowded places & $\begin{array}{c}\text { Unfilled/ } \\
\text { spacious places }\end{array}$ & theaters, and grocery stores. \\
\hline & Diagnostic Test & Viral Test & - & $\begin{array}{l}\text { A test that tests to see if one is } \\
\text { infected. }\end{array}$ \\
\hline & Epidemic & Disease & Pandemic & $\begin{array}{l}\text { A significant and possibly sudden } \\
\text { increase in the number of cases of a } \\
\text { disease in the community. It could be } \\
\text { from one to three countries. }\end{array}$ \\
\hline & $\begin{array}{l}\text { Flattening the } \\
\text { curve }\end{array}$ & Control & - & $\begin{array}{l}\text { Controlling the rate of new cases of } \\
\text { COVID-19. The "curve" refers to a } \\
\text { graph showing the number of cases of } \\
\text { COVID-19 }\end{array}$ \\
\hline & Immunity & Resist or Exemption & & $\begin{array}{l}\text { The body's ability to resist or fight off } \\
\text { an infection. }\end{array}$ \\
\hline & $\begin{array}{l}\text { Presumptive } \\
\text { positive case }\end{array}$ & Confirmed positive case & Negative & $\begin{array}{l}\text { When a person tests positive for the } \\
\text { coronavirus but the centre for disease } \\
\text { control is yet to confirm the case. }\end{array}$ \\
\hline & Quarantine & Isolation & - & $\begin{array}{l}\text { To keep people away from one another } \\
\text { so as to prevent the spread of disease. }\end{array}$ \\
\hline & Self-quarantine & Self-isolation & - & $\begin{array}{l}\text { Separating oneself when sick from } \\
\text { healthy individuals to prevent } \\
\text { spreading illness. }\end{array}$ \\
\hline
\end{tabular}

\section{Conclusion}

In this study semantic tools were explored in the analysis of COVID-19 terms. The core tools of antonymy and synonymy were considered germane for a thorough investigation of the lexical items selected in the COVID-19 glossaries. The primary interest has been in establishing the standard meaning for the selected terms and also existing relationship among the terminologies. From literature, it was discovered that language variations in specific domains hampers communication efforts thereby stalling meaningful development and advancements in such directions. From the foregoing therefore, it could be concluded that semantics analysis is applicable to the vocabulary of COVID-19. In specific terms, the semantic functions of antonymy, and synonymy proved useful tools in identifying the interrelatedness of the selected terms. The study concludes by affirming that meaning can be realized and maintained globally by establishing relationship among words. The research work stands to benefit linguists and educationists in the study of word relations, especially in the notion of similarity and opposition. Specifically, learners of English as a foreign language will get more familiar with the concept of meaning in language studies.

\section{References}

Abioye, T. O. (2018). By words they were created: The synergy between language, discourse and the media in the construction of realities. 12th Inaugural Lecture of Covenant University, Inaugural Lecture Series, 7(2), 5.

Ahamada, J. K., Jauharib, A. H., Luddinc, S. A., \& Abdurahmand, A. J. (2019). Halliday's seven language functions: Lesson guides for teaching/learning English discipline. Retrieved from Microsoft Word - 10615 Ahmad 2019 E.docx (ijicc.net).

Alanagreh, L. a., Alzoughool, F., \& Atoum, M. (2020). The human coronavirus disease COVID-19: Its origin, characteristics, and insights into potential drugs and its mechanisms. Pathogens, 9(5), 331.Available at: https://doi.org/10.3390/pathogens9050331.

Asif, M., Zhiyong, D., Iram, A., \& Nisar, M. (2020). Linguistic analysis of neologism related to coronavirus (COV ID-19). Retrieved from https://ssrn.com/abstract $=3608585$.

Becker, A. (2020). COVID-19 crisis catalog: A glossary of terms. Retrieved from https:www//tmc.edu.news/2020/05/covid-19-crisiscatalog-a-glossary-of-terms/

Bennet, J. M. (2013). The SAGE encyclopedia of intercultural competence. London: SAGE Publicity Inc.

Chiluwa, I., \& Odebunmi, A. (2016). On terrorist attacks in Nigeria: Stance and engagement in conversations on Nairaland. Communication and the Public, 1(1), 91-109.Available at: https://doi.org/10.1177/2057047315624926. 
Chong, C. S. (2011). What is systemic functional grammar? Retrieved from https://chiasuanchong.com/2011/05/17/what-is-systemicfunctional-grammar-part-1/.

De Wit, E., van Doremalen, N., Falzarano, D., \& Munster, V. J. (2016). SARS and MERS: Recent insights Into emerging coronaviruses. Nature Reviews. Microbiology, 14(8), 523-534.Available at: https://doi.org/10.1038/nrmicro.2016.81.

Deng, H. (2020). Register framework: An effective mode for assessing argumentative writing advances in social science, education and humanities research. Paper presented at the International Conference on Advanced Education, Management and Humanities (AEMH 2019).

Djachy, K., Kuparadze, G., \& Rukhiashvili, L. (2018). Linguistic and sociolinguistic peculiarities of family law legal terminology. Theory and Practice in Language Studies, 8(4), 365-374.Available at: https://doi.org/10.17507/tpls.0804.01.

Edet, L. U. (2020). A semantic analysis of supply chain management terms in international trade. An Unpublished PHD Thesis of the Languages and General Studies Department, Covenant University, Nigeria.

Goddard, C. (2013). Semantic analysis: A practical introduction. Oxford: Oxford University Press.

Goddard, C., \& Schalley, A. C. (2010). Semantic analysis. In Indurkhya, N. \& Damerau, F. J. (Eds.), Handbook of natural language processing Chapter 5 (2nd ed., pp. 92-120). London: Taylor \& Francis Group.

Gregory, M., \& Carroll, S. (2020). Language and situation: Language varieties and their social contexts (1st ed.): Routledge.

Guo, Y.-R., Cao, Q.-D., Hong, Z.-S., Tan, Y.-Y., Chen, S.-D., Jin, H.-J., \& Yan, Y. (2020). The origin, transmission and clinical therapies on coronavirus disease 2019 (COVID-19) outbreak-an update on the status. Military Medical Research, 7(1), 1-10.Available at: https://doi.org/10.1186/s40779-020-00240-O.

Halliday, M. A. K., Teubert, W., Yallop, C., \& Cermakova, A. (2004). Lexicology \& corpus linguistics: An introduction. London: Continuum.

Huang, J., Wang, Z., Chang, K. C., Hwu, W., \& Xiong, J. (2020). Exploring semantic capacity of terms. Retrieved from https://arxiv.org/abs/2010.01898.

Ikupa, J. O., \& Akpere, E. G. (2019). A Lexical analysis of select news reports in three Nigerian newspapers. International Journal of Innovative Language, Literature \& Art Studies, 7(1), 58-65.

Jarus, O. (2020). 20 of the worst epidemics and pandemics in history. Live Science contributor, All About history. Retrieved from 20 of the worst epidemics and pandemics in history | Live Science.

Kandola, A. (2020). Coronavirus cause: Origin and how it spreads.

Korneeva, A., Kosacheva, T., \& Parpura, O. (2019). Functions of language in the social context. Paper presented at the SHS Web of Conferences. EDP Sciences.

Kumar, D., Malviya, R., \& Sharma, P. K. (2020). Corona virus: A review of COVID-19. EJMO, 4(1), 8-25.

Ling, Z. (2013). Register theory in functional linguistics and its implication in language teaching. Paper presented at the International Conference on Educational Research and Sports Education (ERSE 2013).

Mayes, P. (2003). Language, social structure, and culture: A genre analysis of cooking classes in Japan and America: John Benjamins Publishing.

Meštrović, A., Martinčić-Ipšić, S., \& Čubrilo, M. (2007). Weather forecast data semantic analysis in f-logic. Journal of Information and Organizational Sciences, 31(1), 1.Available at: https://doi.org/10.31341/jios.

Nazario, B. (2020). Coronavirus: Glossary of common terms. Retrieved from https:webmd.com/lung/coronavirus-glossary\#1.

Neumann, S. (2016). Quantitative register analysis across languages. Retrieved from file:///C:/Users/pc/Downloads/Quantitative_register_analysis_across_languages.pdf.

Niazi, F. (2016). Register theory. Retrieved from https://www.slideshare.net/FarooqNiazi2/register-Theory.

Nordquist, R. (2018). What is register in linguistics? Retrieved from https:www.thoughtco.com/register-language-style-1692038.

Nugrahanto, A. S. (2017). Literature review and conceptual framework. Retrieved from CHAPTER 2.pdf (uny.ac.id).

Nutakor, A. E. (2013). Register theory. Retrieved from https://www.academia.edu/7113036/REGISTER_THEORY.

Oyeyemi, A., Gberevbie, D. E., \& Ibietan, J. (2021). Citizens' participation and primary healthcare policy implementation in Ogun state, Nigeria: An empirical and systems enquiry. Humanities and Social Sciences Letters, 9(1), 50-57.Available at: https://doi.org/10.18488/journal.73.2021.91.50.57.

Polyakova, L. S., Yuzakova, Y. V., Suvorova, E. V., \& Zharova, K. E. (2019). Peculiarities of translation of English technical terms. Paper presented at the IOP Conference Series: Materials Science and Engineering. IOP Publishing.

Rajani, S., \& Hanumanthappa, M. (2016). Techniques of semantic analysis for natural language processing-a detailed survey. International Journal of Advanced Research in Computer and Communication Engineering, 5(2), 146-149.Available at: https://doi.org/10.17148/IJARCCE.

Soares, L. A. (2017). Analysis of super notícia popular newspaper through a critical and multimodal perspective. Alfa: Revista de Lingüística, 61(3), 657-680.Available at: https://doi.org/10.1590/1981-5794-1711-5.

Szmrecsanyi, B., \& Leuven, K. U. (2019). Register in variationist linguistics. Register Studies, 1(1), 76-79.Available at: https://doi.org/10.1075/rs.18006.szm.

Varone, M., Mayer, D., \& Melegari, A. (2017). Natural language process semantic analysis: Definition. Retrieved from https://www.expertsystem.com/natural-language-process-semantic-analysis-definition/. 